\title{
Antitumor effect of cetuximab in combination with S-1 in EGFR-amplified gastric cancer cells
}

\author{
KAZUMASA FUKUDA, YOSHIRO SAIKAWA, MASASHI TAKAHASHI, TSUNEHIRO TAKAHASHI, \\ NORIHITO WADA, HIROHUMI KAWAKUBO, HIROYA TAKEUCHI and YUKO KITAGAWA
}

\author{
Department of Surgery, School of Medicine, Keio University, Tokyo 160-8582, Japan
}

Received September 13, 2011; Accepted November 1, 2011

DOI: 10.3892/ijo.2011.1279

\begin{abstract}
Overexpression of human epidermal growth factor receptor (EGFR) has been detected in gastric cancer $(\mathrm{GC})$ and is associated with poor outcomes. Combination treatment regimens with EGFR-targeting agents and cytotoxic agents are considered to be a potential therapeutic option for EGFR-overexpressing GC. Herein, we have investigated the effects of combination treatment with the oral fluoropyrimidine S-1 and the EGFRtargeting agent cetuximab in GC cells with or without EGFR overexpression. EGFR expression was determined by FACS and quantitative PCR in GC cells. Experimental 5-fluorouracil $(5 \mathrm{FU})$ was used instead of S-1 for in vitro experiments. The efficacy of $5 \mathrm{FU}$ or cetuximab monotherapy or combination $5 \mathrm{FU} /$ cetuximab therapy was examined in vitro and in vivo. Clinical specimens were examined for EGFR by immunohistochemistry (IHC). EGFR expression score was defined as strong membrane and cytoplasmic staining in at least $50-75 \%$ of cells. The combination of 5FU and cetuximab synergistically inhibited cell proliferation and exhibited an enhanced proapoptotic effect in GC cells with EGFR overexpression. Cetuximab also induced down-regulation of phosphorylation of EGFR and AKT, leading to diminished signaling. The antitumor effect of the combination of S-1 and cetuximab in vivo was also greater than that of either drug alone. Our preclinical findings thus indicate that the combination of S-1 and EGFR-targeting therapy is a promising treatment option for GC with EGFR overexpression.
\end{abstract}

\section{Introduction}

Adenocarcinoma of the stomach is the leading cause of gastrointestinal cancer in the world and is the second leading

Correspondence to: Dr Yoshiro Saikawa, Department of Surgery, School of Medicine, Keio University, 35 Shinanomachi, Shinjuku-ku, Tokyo 160-8582, Japan

E-mail: saiky@sc.itc.keio.ac.jp

Abbreviations: GC, gastric cancer; EGFR, epidermal growth factor receptor

Key words: human epidermal growth factor receptor, cetuximab, $\mathrm{S}-1$, gastric cancer, combination therapy cause of cancer death worldwide (1). Currently available chemotherapy for advanced gastric cancer (GC) includes fluoropyrimidine-based agents. S-1 (TS-1) is an orally active combination of tegafur (a prodrug that is converted by cells to fluorouracil), gimeracil (an inhibitor of dihydropyrimidine dehydrogenase, which degrades fluorouracil) and oteracil (which inhibits the phosphorylation of fluorouracil in the gastrointestinal tract, thereby reducing the gastrointestinal toxic effects of fluorouracil) in a molar ratio of 1:0.4:1 $(2,3)$. Results of the large-scale ACTS-GC (adjuvant chemotherapy trial of S-1 for gastric cancer) trial, which enrolled patients with locally advanced (stage II or III) GC who underwent D2 surgery, indicated that $\mathrm{S}-1$ is an effective adjuvant treatment in this patient population. Other clinical trials have reported response rates of 30-50\% for S-1 in advanced GC (4-6). Based on these results, $\mathrm{S}-1$ is now recognized as one of the standard chemotherapeutic agents for this disease $(7,8)$.

Although advanced GC is treated predominantly by combination chemotherapy regimens that include fluoropyrimidine derivatives, overall survival (OS) can still be improved $(9,10)$. Investigational chemoradiotherapy regimens have also left room for improvement. In recent years, substantial advances have been made in the development of molecularly targeted therapies for various types of cancer. Targeted therapies block the growth of cancer cells by interfering with specific molecules required for carcinogenesis and tumor growth (11). Targeted cancer therapies have the potential to be more effective than current treatments and less harmful to normal cells.

Overexpression of human epidermal growth factor receptor 1 (EGFR; ErbB1; HER1 in humans) has been detected in approximately $30-70 \%$ of GC cases and is associated with poor outcomes and aggressive disease $(12,13)$. EGFR status was reported to be significantly associated with OS and relapse-free survival (RFS) in both the surgery alone group and the S-1 group in the ACTS-GC study (Terashima M, et al, 2011 ASCO Meeting, 4013). Progress in the understanding of the involvement of the EGFR pathway in GC has recently been made. The binding of a ligand to the extracellular portion of EGFR results in phosphorylation of the tyrosine kinase domain located in the intracellular portion, resulting in activation of intracellular effectors involved in signaling, such as the $\mathrm{G}$ protein $\mathrm{K}$-ras and the protein kinase RAF [Ras/mitogen-activated protein kinase pathway (MAPK)], as well as phosphoinositide 3-kinase (PI3K/Akt pathway). 
Cetuximab is a chimeric (mouse/human) IgG1monoclonal antibody directed against EGFR that is administered by intravenous infusion for treatment of metastatic colorectal cancer and head and neck cancer. Cetuximab has been proven to be effective in irinotecan-resistant metastatic colorectal cancer expressing EGFR, detected by immunohistochemistry (IHC), with response rates ranging from $8.8 \%$ when used as monotherapy to $22.9 \%$ when combined with irinotecan $(14,15)$. Despite recent advances in the molecular understanding of $\mathrm{GC}$, there is a noticeable lack of targeted therapies in clinical development for this malignancy.

In this study, we investigated whether cetuximab alone or in combination with S-1 can be used in the treatment of EGFRoverexpressing GC in cell culture and xenograft models as an indication of its potential efficacy for treating patients with GC.

\section{Materials and methods}

Cell culture and reagents. Human GC cell lines (MKN45, KATOIII, MKN74, MKN28 and MKN1) were obtained from the Japanese Cancer Research Resources Bank (Tokyo, Japan). MKN45 and KATOIII cells were derived from poorlydifferentiated adenocarcinomas. MKN74 and MKN28 cells were derived from moderately- and well-differentiated adenocarcinomas, respectively. The MKN1 cell line is a gastric adenocarcinoma cell line obtained from a metastatic lymph node and has the ability to differentiate into either adenomatous or squamous cells. The KGC01 line was obtained from a patient with clinically diagnosed GC with a pathological diagnosis of type 4 carcinoma (pT4N1H0CY1M0/stage IV); this patient provided informed consent (approved by the ethics committee of Keio University; no. 17-47). These cell lines were cultured in RPMI-1640 (Sigma, St. Louis, MO) containing $10 \%$ fetal bovine serum (FBS; Invitrogen, Carlsbad, $\mathrm{CA}$ ) and penicillin-streptomycin mixed solution (penicillin 10,000 units $/ \mathrm{ml}$, streptomycin $10,000 \mu \mathrm{g} / \mathrm{ml}$; Nacalai Tesque, Inc., Kyoto, Japan). In all experiments, cells were cultured at $37^{\circ} \mathrm{C}$ in a humidified $5 \% \mathrm{CO}_{2} / 95 \%$ air atmosphere. Cetuximab (Erbitux, Merck, Lyon, France) was obtained from BristolMyers Squibb Co. (New York, NY), 5FU was obtained from Kyowa Hakko Kirin Co., Ltd. (Tokyo, Japan) and tegafur, gimeracil and oteracil, all of which are components of S-1, were synthesized by Taiho Pharmaceutical.

Analysis of EGFR expression. To detect expression of EGFR, cells were removed from the culture dish using trypsin and EDTA, pelleted by centrifugation, washed with phosphatebuffered saline (PBS) and resuspended at $37^{\circ} \mathrm{C}$ in Hanks' balanced salt solution (HBSS) containing $2 \% \mathrm{FBS}$ and $10 \mathrm{mM}$ HEPES (Invitrogen). Cells were incubated with Blocking One solution (Nacalai Tesque) for $20 \mathrm{~min}$ at room temperature. They were then washed and incubated with anti-human EGFR antibody conjugated with FITC (BD Pharmingen, San Jose, CA) for $30 \mathrm{~min}$ at $4^{\circ} \mathrm{C}$. Finally, cells were subsequently counterstained with $1 \mu \mathrm{g} / \mathrm{ml}$ propidium iodide (PI; Sigma) to label dead cells. Then, $1 \times 10^{6}$ viable cells were analyzed using a FACSVantage $^{\mathrm{TM}}$ SE (Becton-Dickinson, San Jose, CA). The distribution of cells was analyzed using FlowJo software (Tomy Digital Biology, Tokyo, Japan).
Quantitative RT-PCR. Total RNA from cells was extracted using an RNeasy Mini Kit (Qiagen, Hilden, Germany) according to the manufacturer's protocol. The concentration of total RNA was determined using a NanoDrop ND-1000 (NanoDrop Technologies, San Diego, CA). Briefly, purified total RNA was reverse-transcribed to generate double-stranded cDNA using Eagle Taq Master Mix with ROX (Roche Applied Science, Indianapolis, IN) and the expression of human EGFR was analyzed using the Applied Biosystems 7500 Fast RealTime PCR System (Applied Biosystems, Foster City, CA). TaqMan gene expression assay primers and probe mixes were used for GAPDH and EGFR (assay IDs Hs99999905_m1 and Hs01076078_m1, respectively; Applied Biosystems). GAPDH was detected using TaqMan primers and probes and was used as the control gene. The thermal cycling reaction included incubation at $95^{\circ} \mathrm{C}$ for $20 \mathrm{sec}$ and 40 cycles of $95^{\circ} \mathrm{C}$ for $3 \mathrm{sec}$ and $60^{\circ} \mathrm{C}$ for $30 \mathrm{sec}$. Data were collected using analytical software (Applied Biosystems). Using the $\Delta \Delta \mathrm{C}_{\mathrm{T}}$ method, the expression level of each gene was determined relative to the value of the expression of the gene in TMK-1 cells.

DNA extraction and $K$-ras mutation analysis. DNA was extracted from GC cell lines using a QIAmp DNA Mini kit (Qiagen, Duesseldorf, Germany). A NanoDrop ND-1000 (NanoDrop Technologies) was used to evaluate the concentration of the samples. The reaction mixes contain a single primer set specific for either the wild-type or mutated sequences in codons 12 and 13 of K-ras. Direct sequencing was done using a Big Dye Terminator cycle sequencing kit (Applied Biosystems) and analyzed on an ABI PRISM 310 DNA Analyzer automated sequencer (Applied Biosystems).

Survival studies with anticancer agents. Cells were plated in 96-well micro-plates and cultured for $12 \mathrm{~h}$ before exposure to various concentrations of compounds for $72 \mathrm{~h}$. Cells were quantified using the WST- 8 assay. The optical density (OD) value was detected by Rainbo Sunrise (Wako Pure Chemical Industries, Ltd., Osaka, Japan). The rate of inhibition was calculated as follows: \% inhibition $=(\mathrm{OD}$ of treated group blank)/OD of control group x 100. The concentration of tested drugs resulting in $50 \%$ growth inhibition $\left(\mathrm{IC}_{50}\right)$ was calculated. Data were analyzed to determine the combination index (CI), a well-established index of the interaction between two drugs (16). CI values of $<1,1$ and $>1$ indicate synergistic, additive and antagonistic effects, respectively.

Phosphorylation activity assay. To evaluate the dependency of cetuximab activity on EGFR and AKT phosphorylation, cells were exposed to $3.97 \mu \mathrm{M}$ cetuximab for $72 \mathrm{~h}$ before they were collected. Cells were washed in PBS and fixed with $2 \%$ paraformaldehyde (PFA) in a $37^{\circ} \mathrm{C}$ water bath for $10 \mathrm{~min}$. Then, cells were washed with PBS and pelleted by centrifugation $(800 \mathrm{x} \mathrm{g})$ for $5 \mathrm{~min}$ and the supernatant was removed. Cells were mixed to disrupt the pellet and permeabilized by adding $500 \mu 1$ of $90 \%$ methanol (for $1-10 \times 10^{6}$ cells) and incubated on ice for $15 \mathrm{~min}$. After blocking on ice for $10 \mathrm{~min}$, cells were then washed and incubated with primary antibodies against EGFR, AKT, phospho-EGFR (Tyr1068) and phospho-AKT (Ser473) (Cell Signaling Technology, Inc., Danvers, MA) for $60 \mathrm{~min}$ at room temperature. Cells were washed with PBS before incuba- 
Table I. EGFR status and K-ras mutation in gastric cancer.

\begin{tabular}{lccr}
\hline Cell line & $\begin{array}{c}\text { EGFR protein expression } \\
(\%, \text { mean } \pm \text { SD })\end{array}$ & $\begin{array}{c}\text { EGFR mRNA amplification } \\
\text { (fold, mean } \pm \text { SD) }\end{array}$ & K-ras mutation \\
\hline MKN28 & $95.90 \pm 1.23$ & $43.08 \pm 0.53$ & WT \\
MKN45 & $4.16 \pm 0.51$ & $24.57 \pm 0.62$ & WT \\
MKN74 & $4.35 \pm 0.26$ & $15.52 \pm 2.79$ & WT \\
TMK-1 & $2.43 \pm 0.32$ & 1 (control) & WT \\
KATOIII & $3.23 \pm 0.12$ & $38.19 \pm 2.07$ & WT \\
KGC01 & $3.09 \pm 0.19$ & $4.90 \pm 1.12$ & WT \\
\hline
\end{tabular}

EGFR protein expression on the cell surface was detected by flow cytometry. mRNA was purified from GC cell lines and EGFR amplification was analyzed using the Applied Biosystems 7500 Fast Real-Time PCR System. Mutation status of K-ras in cell lines was measured by ABI PRISM 310 DNA analyzer.

tion for 30 min with Alexa Fluor 488 donkey anti-rabbit IgG antibody (Invitrogen). Then, each sample was analyzed using a FACSCalibur ${ }^{\mathrm{TM}}$ (Becton-Dickinson). Cell distribution was analyzed using FlowJo software (Tomy Digital Biology).

Apoptosis assay. For apoptosis assays, the supernatant was aspirated and cells were resuspended in $150 \mu \mathrm{l}$ binding buffer, and stained with $5 \mu \mathrm{l}$ Annexin V-FITC and $5 \mu \mathrm{l}$ PI at room temperature for $25 \mathrm{~min}$ in the dark. After incubation, cells were processed as directed in the kit instructions (Annexin V-FITC Apoptosis Detection Kit I, BD Pharmingen) and analyzed using a FITC signal detector and PI detector using a flow cytometer (FACSCalibur ${ }^{\mathrm{TM}}$ ) and Cell Quest software (BectonDickinson).

In vivo multiple drug assay. MKN28 cells $\left(1 \times 10^{6}\right)$ were implanted s.c. into the axilla of 6-week-old male athymic nude mice. Drug administration was initiated when tumors in each group achieved an average volume of $333 \pm 2.16 \mathrm{~mm}^{3}$. Mice were randomly allocated to control and treatment groups. Treatment groups consisted of control, S-1 alone, cetuximab alone and combination $\mathrm{S}-1 /$ cetuximab. Each treatment group included 8 mice. S-1 was administered at a dose of $6.9 \mathrm{~g} / \mathrm{kg} /$ day and given by oral gavage daily for 14 days. Cetuximab ( $40 \mathrm{mg} / \mathrm{kg} /$ day) was given i.p. on Days 1,4,8 and 14. Control animals received sterile PBS administration. Tumor volume was determined from caliper measurements of tumor length (L) and width (W) according to the formula $\mathrm{LW}^{2} / 2$ and on body weights acquired every 3 days and on the day of evaluation. Both tumor size and body weight were measured three times per week. The percentage of tumor growth inhibition (TGI\%) was calculated as follows: TGI $(\%)=$ [1 - (tumor volume of treatment group on evaluation day - tumor volume of treatment group on Day 1)/(tumor volume of control group at evaluation day - tumor volume of control group on Day 1)] x 100. The percentage of body weight change (BWC\%) was calculated as follows: BWC $(\%)=[(\mathrm{BW}$ on evaluation day $)-$ (BW on Day 1)]/(BW on Day 1) x 100.

Immunohistochemical analysis. Samples were fixed with 4\% PFA for $24 \mathrm{~h}$ at RT. Immunohistochemical staining for EGFR was performed on $4-\mu \mathrm{m}$ thick sections placed on precoated slides with APS (Matsunami Glass Ind., Ltd., Osaka,
Japan). Briefy, slides were incubated with blocking reagentN101 (Wako Pure Chemical Industries, Tokyo, Japan) for $20 \mathrm{~min}$. After rinsing in PBST, avidin and biotin blocking was performed for $15 \mathrm{~min}$ each. Slides were incubated with anti-human EGFR monoclonal antibody (Cell Signaling Technology, Inc.). EnVision ${ }^{\mathrm{TM}}+$, Rabbit/HRP (Dako, Glostrup, Denmark) was then used as secondary antibody for $30 \mathrm{~min}$. DAB staining reactions were conducted for $10 \mathrm{~min}$. Slides were counterstained with haematoxylin. Finally, slides were cover-slipped with aqueous mounting medium (Aquatex ${ }^{\circledR}$, Merck). Specimens were analyzed under a light microscope, and EGFR positivity was defined as strong membrane and cytoplasmic staining in at least $50-75 \%$ of cells.

Statistical methods. All data were expressed as the mean \pm SD. Statistically significant differences were determined using two-tailed Student's t-test or $\chi^{2}$ test. P-values $<0.05$ were considered statistically significant.

\section{Results}

Profile of EGFR amplification in GC cells. To evaluate EGFR amplification and K-ras mutation status, six GC cell lines (MKN28, MKN45, MKN74, KATOIII, TMK-1 and KGC01) were examined for their expression of EGFR protein and mRNA by flow cytometry and real-time PCR and for mutation analysis by direct sequencing. FACS analysis revealed that EGFR expression was significantly higher in MKN28 cells compared to other cell lines $(\mathrm{P}<0.05)$ (Fig. 1A). The EGFR mRNA expression ratio of each cell line was determined relative to the value of TMK-1. The EGFR mRNA level was 43.08 \pm 0.53 -fold for MKN28 cells, 24.57 \pm 0.62 -fold for MKN45 cells, $15.52 \pm 2.79$-fold for MKN74 cells, 38.19 \pm 2.07 -fold for

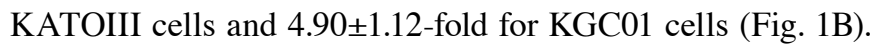
$\mathrm{K}$-ras mutation status for each cell line is shown in Table I. Among the GC cell lines examined, EGFR protein and mRNA were overexpressed in MKN28 cells, while KATOIII cells showed amplification of EGFR mRNA, but were negative for EGFR protein expression.

Synergistic anti-proliferative effects of $5 F U$ and cetuximab in EGFR-amplified GC cells. The effects of 5FU or cetuximab 
A
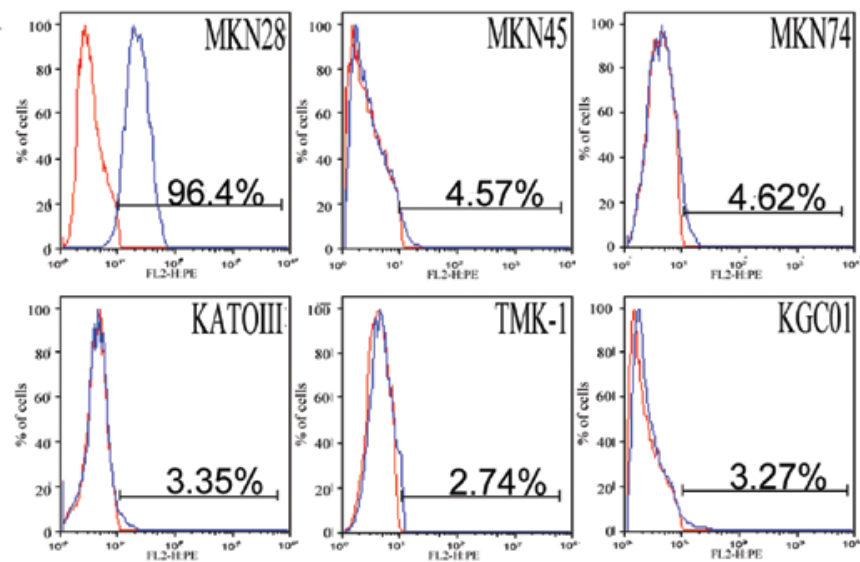

B

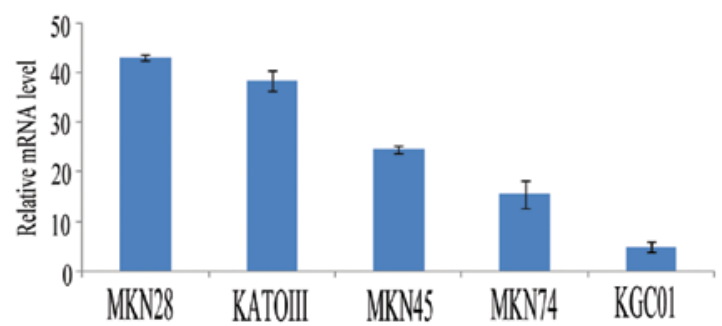

Figure 1. Analysis of EGFR expression in human GC cell lines. (A) Flow cytometric analysis of EGFR expression in human GC cell lines. Cells were treated with monoclonal antibodies against human EGFR. Expression levels were estimated by the intensity of fluorescence with phycoerythrin (PE) in the samples (red histogram, isotype control; blue histogram, cetuximab). (B) Relative mRNA expression of EGFR in GC cell lines was determined using a quantitative real-time RT-PCR amplification analysis. Results were analyzed using the relative quantification $\left(\Delta \Delta \mathrm{C}_{\mathrm{T}}\right)$ method.

A

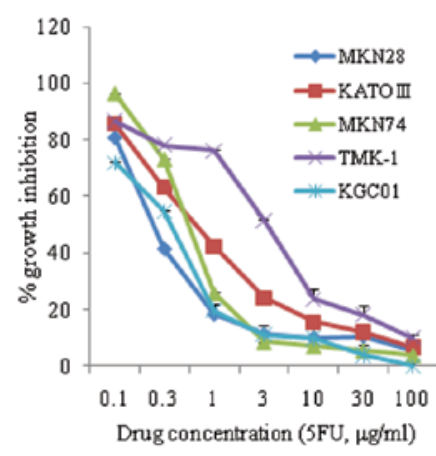

B

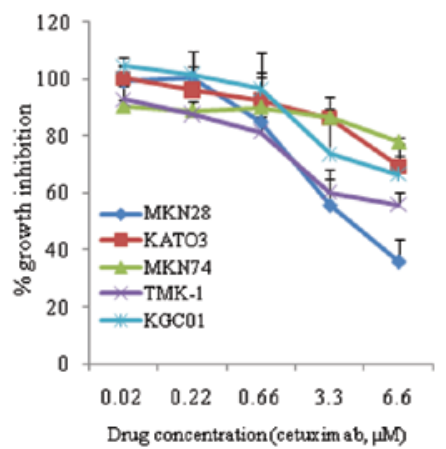

$\mathrm{C}$

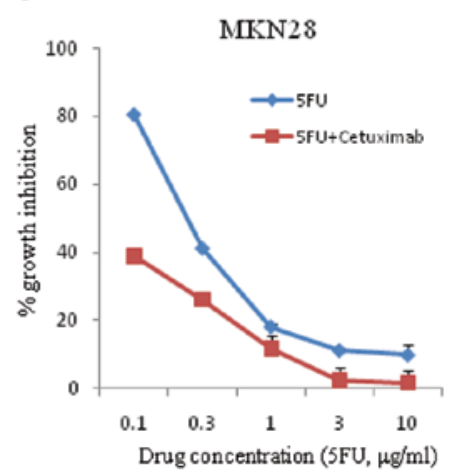

$\mathrm{D}$

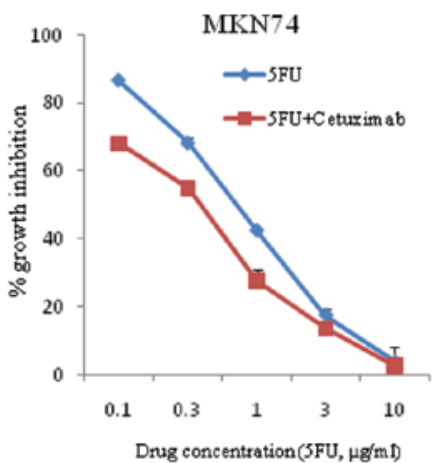

$\mathrm{E}$

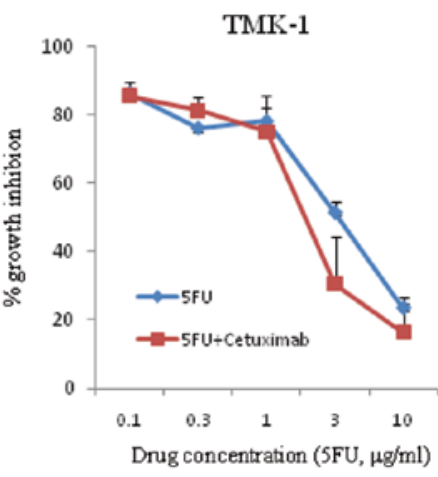

$\mathrm{F}$

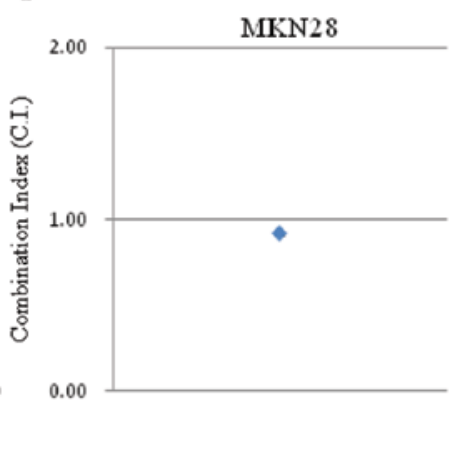

Figure 2. Anti-proliferative effects of 5FU monotherapy, cetuximab monotherapy and combination 5FU/cetuximab in vitro. (A, B) GC cells were maintained in supplemented medium for $12 \mathrm{~h}$ and then incubated with $5 \mathrm{FU}(0.1-100 \mu \mathrm{g} / \mathrm{ml})$ or cetuximab $(0.02-6.6 \mu \mathrm{M})$ for $72 \mathrm{~h}$. (C-E) EGFR-amplified MKN28 cells or non-EGFR-amplified MKN74 and TNK-1 cells were incubated for $72 \mathrm{~h}$ with $5 \mathrm{FU}(0-10 \mu \mathrm{g} / \mathrm{ml})$ and cetuximab at a fixed cetuximab concentration of $3.97 \mu \mathrm{M}$, after which cell viability was measured. (F) The interaction between the two agents was evaluated on the basis of the CI. CI values of $<1,1$ and $>1$ indicate synergistic, additive and antagonistic effects, respectively. Data are means of triplicates from a representative experiment. 
A
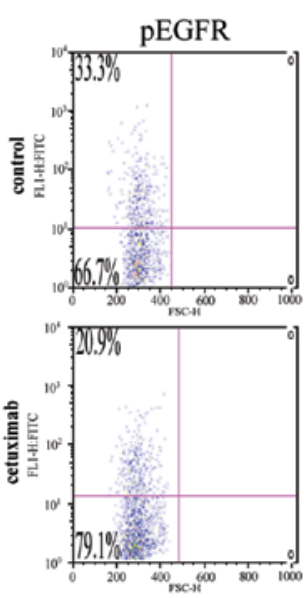

$\mathrm{C}$

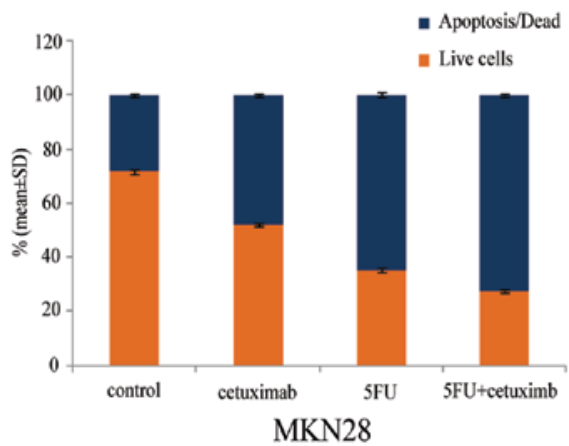

MKN28
B
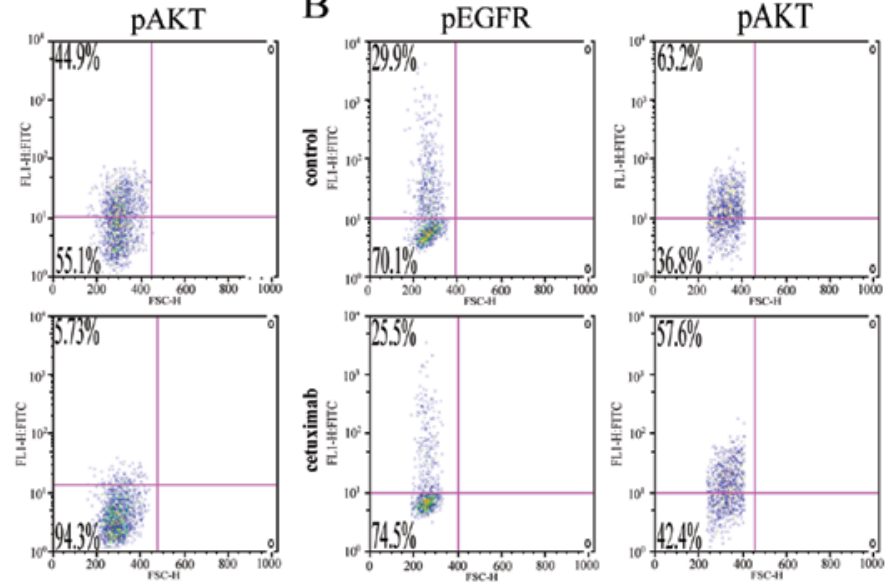

TMK-1

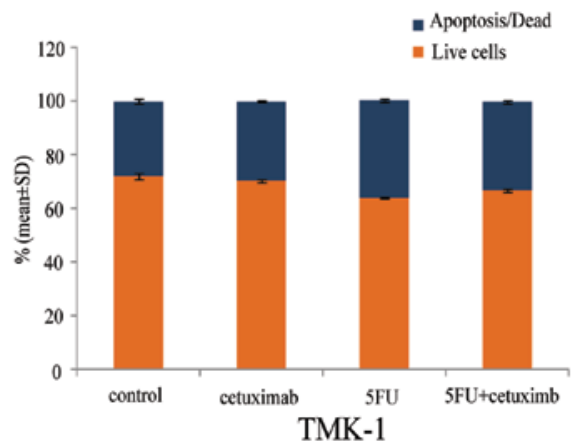

Figure 3. Effect on cell signaling and apoptosis. (A, B) Cells were treated with $3.97 \mu \mathrm{M}$ cetuximab for $72 \mathrm{~h}$. Decreased pEGFR and pAKT activity is observed following cetuximab treatment in EGFR-amplified MKN28 cells, but not in non-EGFR-amplified TMK-1 cells. (C) The effect of 5FU and cetuximab on apoptosis in EGFR-amplifed GC cells. MKN28 and TMK-1 cells were treated for $72 \mathrm{~h}$ with each agent alone or combination 5FU/cetuximab. The proportion of apoptotic cells was assessed by staining with FITC-conjugated Annexin V and PI followed by flow cytometry. Data are the means \pm SD from three independent experiments.

monotherapy or combination 5FU/cetuximab therapy on the growth of GC cells with and without EGFR amplification were evaluated. $5 \mathrm{FU}$ was used instead of $\mathrm{S}-1$ for these in vitro experiments, since tegafur, a component of $\mathrm{S}-1$, is metabolized to $5 \mathrm{FU}$ in the liver. The combined effect of $5 \mathrm{FU}$ and cetuximab was evaluated on the basis of the CI. 5FU monotherapy inhibited the proliferation of GC cells, although the $\mathrm{IC}_{50}$ values varied significantly between the individual cell lines (Fig. 2A and B). On the other hand, EGFR-amplified MKN28 cells showed only sensitive to cetuximab in a concentrationdependent manner compared with other GC cells (Fig. 2C). The combination of 5FU and cetuximab exhibited a synergistic inhibitory effect on the growth of EGFR-amplified MKN28 cells (C.I. value $=0.92 \pm 0.015$ ), but not on cells without EGFR amplification, including MKN74 and TMK-1 cells (Fig. 2C-F).

Effect of cetuximab on EGFR and AKT signaling in GC cells. EGFR can signal through the AKT or MAPK pathways (17). To explore the anti-proliferation mechanism of EGFR-targeted agents, we examined the effects of cetuximab on the EGFR/ AKT signaling pathway. MKN28 and TMK-1 cells were treated with cetuximab for $72 \mathrm{~h}$. In the EGFR-amplified cell line MKN28, cetuximab decreased both EGFR and AKT phosphorylation when compared with the isotype controls. In contrast, phosphorylation of EGFR or AKT was not affected by cetuximab in TMK-1 cells, in which EGFR is not amplified (Fig. 3A). These data indicate that cetuximab can suppress the activation of key pathways that are downstream of EGFR.

Enhanced induction of apoptosis by combined $5 F U$ and cetuximab in EGFR-amplified GC cells. To investigate the mechanism underlying the synergistic growth inhibition induced by combination of 5FU and cetuximab, we examined the effects of each agent alone and in combination on apoptosis in GC cells. An assay based on the binding of Annexin V to the cell surface revealed that the frequency of apoptosis was markedly greater in EGFR-amplified cells treated with both $5 F U$ and cetuximab than in cells treated with either agent alone (Fig. 3B). No such effect was observed in cells negative for EGFR amplification. These data indicate that the combination of 5FU and cetuximab exhibits an enhanced apoptotic effect in EGFR-amplified GC cells, but not in those without EGFR amplification.

Effects of combination cetuximab and $S$-1 therapy on EGFRoverexpressing human GC xenograft models. The antitumor activities of cetuximab combined with chemotherapy were examined in an EGFR-overexpressing human GC xenograft model. Mice with tumors derived from MKN28 cells were 
A

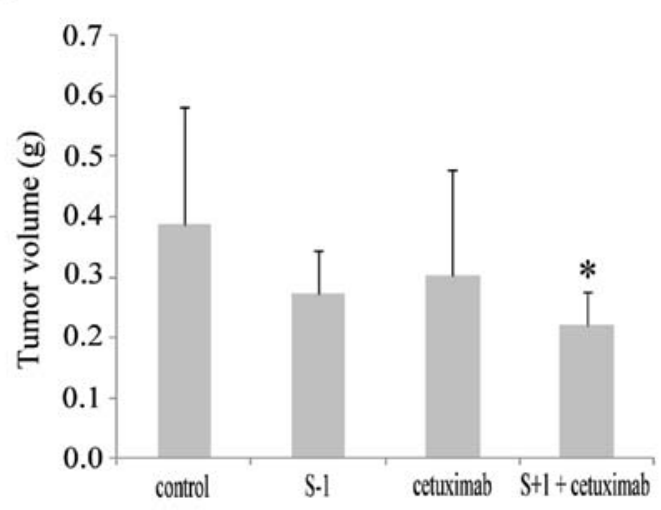

$\mathrm{C}$
B

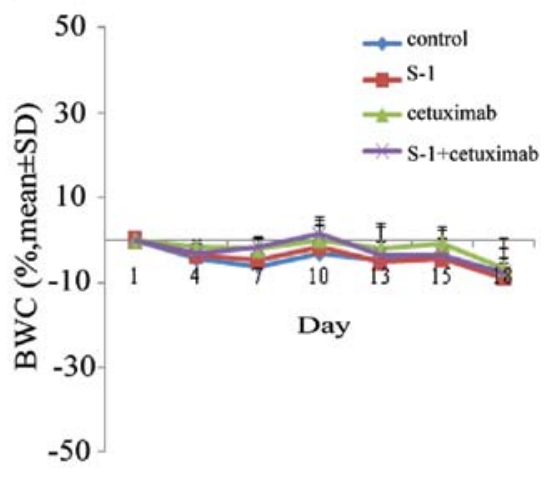

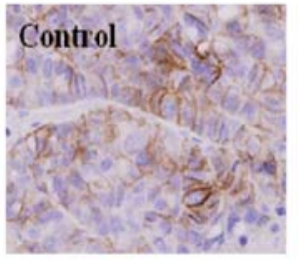
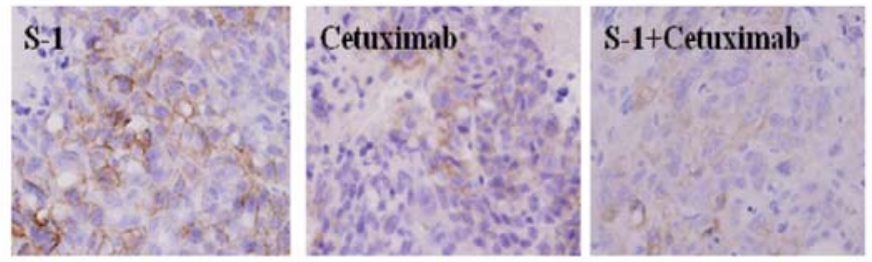

Figure 4. Antitumor activity of cetuximab and S-1 on tumor growth in an EGFR-amplified xenograft model. MKN28 cells (1x10 ${ }^{6}$ cells with 50\% Matrigel) were injected s.c. into nude mice and mice were randomized into four groups ( $\mathrm{n}=8 / \mathrm{group})$. Treatment started when tumors in each group achieved an average volume $\left(333 \pm 2.16 \mathrm{~mm}^{3}\right)$ with S-1 (6.9 mg/kg daily for 14 days), cetuximab (40 mg/kg i.p. on Days $1,4,8$ and 14), sterile PBS (control) or combination S-1/ cetuximab (same doses as above). Tumor sizes and body weights were measured every 3 days. (A) Student's t-test was used to compare tumor volume (g) between groups at the end of the experiment; results are presented as means. Error bars represent SD of the mean ( $\mathrm{P}<0.05)$. (B) All treatments were well tolerated by the mice, with no signs of toxicity or weight loss during therapy. (C) Tumor tissues of each treatment group were examined for expression of EGFR protein by IHC. *Statistically significant.

divided into groups for treatment with vehicle, $S-1$, cetuximab, or combined S-1/cetuximab for 14 days. Tumor volume (TV) was evaluated between groups at the end of the experiment. The TV ( $\mathrm{g}$ ) for combined S-1/cetuximab was $0.22 \pm 0.05 \mathrm{~g}$, whereas for control, $\mathrm{S}-1$ and cetuximab alone was $20.0 \pm 1.96 \mathrm{~g}$, $0.27 \pm 0.07 \mathrm{~g}$ and $0.30 \pm 0.17 \mathrm{~g}$, respectively. Additionally, the TGI \% for cetuximab combined with S-1 was $43.2 \%$, while that for S-1 and cetuximab alone was 29.8 and $22.4 \%$, respectively. Combination S-1/cetuximab therapy inhibited the growth of tumors formed by EGFR-amplified MKN28 cells compared to treatment with either agent alone $(\mathrm{P}<0.05)$ (Fig. 4A). All treatments were well tolerated by the mice, with no signs of toxicity or weight loss during therapy (Fig. 4B). Furthermore, tumors in each treatment group were examined for expression of EGFR protein by IHC. EGFR expression was decreased in the cetuximab alone and the $\mathrm{S}-1 /$ cetuximab groups compared to the control and S-1 alone groups (Fig. 4C). Thus, the combination $\mathrm{S}-1 /$ cetuximab therapy appears to result in an enhanced antitumor effect in EGFR-amplified GC xenografts, consistent with the results obtained in vitro.

EGFR expression in patients with GC. Among the 40 specimens, the median age of patients was 67 years (range, 32-94 years); 20 patients had differentiated carcinoma and the other half had undifferentiated carcinoma. Formalin-fixed paraffin-embedded specimens from all 40 patients were examined for EGFR by IHC (Fig. 5). Analysis of EGFR protein expression by microscopic observation revealed a score of 0

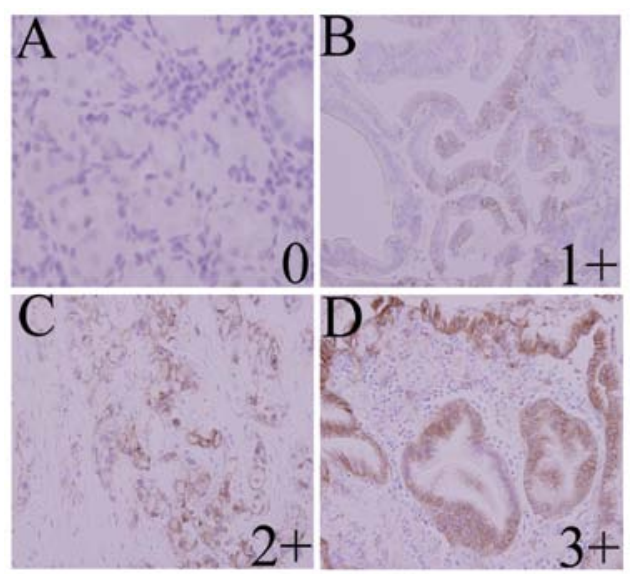

Figure 5. Image analysis of GC clinical specimens immunostained with anti-human EGFR monoclonal antibody. Immunohistochemical staining was performed by the peroxidase method. A-D were scored $0,1+, 2+$ and $3+$, respectively, in quantitative analysis, according to the EGFR pharmDx ${ }^{\mathrm{TM}}$ Interpretation Manual (magnification, x200).

in 24 cases $(60 \%), 1+$ in 5 cases $(12.5 \%), 2+$ in 6 cases $(15 \%)$ and $3+$ in 5 cases $(12.5 \%)$. EGFR reactivity was not correlated with gender, age, differentiation, lymph node metastasis or distant metastasis. Significantly more clinicopathological stage III/IV cases had EGFR-positive disease (30\%) compared to stage I/II cases $(10 \%, \mathrm{P}=0.0088)$ (Table II). These results indicate that EGFR positivity is associated with advanced disease in GC. 
Table II. Association between EGFR status and clinicopathological characteristics of patients including gender, age, stage, differentiation and metastasis.

\begin{tabular}{lccc}
\hline & $\begin{array}{c}\text { Positive } \\
\text { patients }(\%)\end{array}$ & $\begin{array}{c}\text { Negative } \\
\text { patients }(\%)\end{array}$ & P-value \\
\hline Total & $16(40.0)$ & $24(60.0)$ & \\
Gender & & & \\
Male & $14(35.0)$ & $14(35.0)$ & 0.078 \\
Female & $2(5.0)$ & $10(25.0)$ & \\
Age & & & \\
$<70$ & $9(22.5)$ & $7(17.5)$ & 0.109 \\
$\geq 70$ & $7(17.5)$ & $17(42.5)$ & \\
Stage & & & \\
IA/IB/II & $4(10.0)$ & $17(42.5)$ & 0.008 \\
IIIA/IIIB/IIIC/IV & $12(30.0)$ & $7(17.5)$ & \\
Differentiation & & & \\
Differentiated & $9(22.5)$ & $11(27.5)$ & 0.747 \\
Undifferentiated & $7(17.5)$ & $13(32.5)$ & \\
Lymph node & & & 0.100 \\
metastasis & & & \\
Absent & & & \\
Present & $3(7.5)$ & $12(30.0)$ & 0.999 \\
Distant metastasis & $12(30.0)$ & $13(32.5)$ & \\
Absent & $15(37.5)$ & $22(55.0)$ & \\
Present & $(2.5)$ & & \\
\hline
\end{tabular}

\section{Discussion}

EGFR amplification has been suggested to be associated with prognosis in gastrointestinal carcinoma. Cetuximab is a chimeric anti-EGFR monoclonal antibody that inhibits signaling pathways affecting cellular growth, differentiation and proliferation (18). Cetuximab is widely used as a standard therapy for EGFR-positive colorectal and head and neck cancer, and shows clinical efficacy both alone and in combination with chemotherapeutic agents (19-23). However, only limited evaluation of EGFR-targeted agents has been conducted in GC models and most such studies have been restricted to EGFRamplified cells. Furthermore, the mechanisms of action of EGFR-targeted agents in combination with cytotoxic agents have remained unclear. In the present study, we have shown that the combination of S-1 (or 5FU) and EGFR-targeted therapy results in a synergistic antitumor effect in EGFR-amplified GC cells, but not in those lacking EGFR amplification.

To explore the efficacy of cetuximab alone or in combination with S-1 in EGFR-overexpressed GC, we evaluated the effect of cetuximab in a panel of molecularly characterized human GC cell lines. The level of EGFR protein expression was determined for a panel of six human GC cancer cell lines, and mRNA status was assessed by real-time PCR. Doseresponse curves were generated to determine sensitivity to $5 \mathrm{FU}$ or cetuximab. Cetuximab had concentration-dependent antiproliferative activity across the panel, with the greatest effects in EGFR-amplified MKN28 cells. In contrast, the EGFR lowexpressing cell lines MKN74 and TMK-1 were less sensitive to cetuximab. Moreover, Fig. 2 shows that the combination of 5FU and cetuximab was highly synergistic in inhibiting cell growth, with a CI of $<1$ in MKN28. Cetuximab inhibited phosphorylation of EGFR (pEGFR) and AKT (pAKR) in EGFR-amplified MKN28 cells, but not in cells without EGFR amplification. Down-regulation of pEGFR and pAKR by cetuximab treatment may therefore enhance 5FU-induced apoptosis. Previous studies reported that activation of EGFR leads to downstream signaling that activates mitogenic and survival pathways, such as the MAPK and PI3-K/AKT pathways (24). Inhibition of these pathways by EGFR antagonists, such as cetuximab, can lead to induction of apoptosis and anti-proliferative effects (25). These results suggest that combination therapy may block the signaling pathways downstream of EGFR. Moreover, the efficacy of cetuximab monotherapy, S-1 monotherapy or combination S-1/cetuximab was examined in an EGFR-amplified xenograft model. In the MKN28 xenograft, combination S-1/ cetuximab induced a near complete tumor regression in all treated mice. In the cetuximab monotherapy and combination S-1/cetuximab treatment groups, EGFR expression was downregulated compared to that of the control and S-1 monotherapy groups, suggested that cetuximab may be blocking combination of ligand and EGFR-driven signaling. The combination therapy effects were more pronounced than either cetuximab or S-1 alone. EGFR expression was required to obtain a positive response to combination S-1/cetuximab, which is consistent with the results of numerous studies demonstrating that the antitumor activity of several anticancer agents increases when combined with cetuximab (26-34).

Clinical specimens from 40 patients with GC were examined for EGFR by IHC. EGFR expression was detected in $40 \%$ (16/40) of clinical specimens. Overall, 30\% of clinicopathological stage III/IV patients demonstrated EGFR positivity $(\mathrm{P}=0.0088)$. These data indicate that EGFR expression is associated with advanced disease in GC. EGFR appears to be a potential target molecule for the treatment of GC. A recently reported phase II clinical trial showed a significant gain in OS for EGFR-positive patients with advanced GC who received combined treatment with cetuximab and FOLFOX6 (35). The present observations provide a rationale for clinical evaluation of combination chemotherapy with S-1 and EGFR-targeted agents according to EGFR amplification status.

In conclusion, the present results demonstrate that the combination cetuximab/S-1 can enhance S-1 antitumor activity. EGFR amplification is the best predictive marker for the anti-proliferative effects of combination chemotherapy with S-1 and cetuximab. The combination of cetuximab and S-1 may be a promising therapeutic strategy for some patients with EGFR-amplified GC.

\section{Acknowledgements}

We thank Taiho Pharmacy Co., Ltd. for provision of compounds and for helpful discussions and we are thankful to Yumi Yoshimura for technical assistance in the experiments.

\section{References}

1. Jemal A, Siegel R, Ward E, et al: Cancer statistics, 2008. CA Cancer J Clin 58: 71-96, 2008. 
2. Mari E, Floriani I, Tinassi A, et al: Efficacy of adjuvant chemotherapy after curative resection for gastric cancer: a meta-analysis of published randomized trials. Ann Oncol 11: 837-843, 2000.

3. Panzini I, Gianni L, Fattori PP, et al: Adjuvant chemotherapy in gastric cancer: a meta-analysis of randomized trials and a comparison with previous meta-analyses. Tumori 88: $21-27$, 2002 .

4. Sakata Y, Ohtsu A, Horikoshi N, Sugimachi K, Mitachi Y and Taguchi T: Late phase II study of novel oral fluoropyrimidine anticancer drug S-1 (1 M tegafur- $0.4 \mathrm{M}$ gimestat- $1 \mathrm{M}$ otastat potassium) in advanced gastric cancer patients. Eur J Cancer 34: 1715-1720, 2008.

5. Koizumi W, Kurihara M, Nakano S and Hasegawa K: Phase II study of S-1, a novel oral derivative of 5-fluorouracil, in advanced gastric cancer. For the S-1 Cooperative Gastric Cancer Study Group. Oncology 58: 191-197, 2000.

6. Koizumi W, Narahara H, Hara T, et al: S-1 plus cisplatin versus $\mathrm{S}-1$ alone for first-line treatment of advanced gastric cancer (SPIRITS trial): a phase III trial. Lancet Oncol 9: 215-221, 2008.

7. Sakuramoto S, Sasako M, Yamaguchi T, et al: Adjuvant chemotherapy for gastric cancer with S-1 an oral fluoropyrimidine. N Engl J Med 357: 1810-1820, 2007.

8. Boku N: Chemotherapy for metastatic disease: review from JCOG trials. Int J Clin Oncol 13: 196-200, 2008.

9. Hartgrink HH, Jansen EP, van Grieken NC and van de Velde CJ: Gastric cancer. Lancet 374: 477-490, 2009.

10. Wesolowski R, Lee C and Kim R: Is there a role for second-line chemotherapy in advanced gastric cancer? Lancet Oncol 10: 903-912, 2009.

11. Ferrara N and Kerbel RS: Angiogenesis as a therapeutic target. Nature 438: 967-974, 2005.

12. Iqbal S, Goldman B, Fenoglio-Preiser CM, Lenz HJ, Zhang W, Danenberg KD, Shibata SI and Blanke CD: Southwest Oncology Group study S0413: a phase II trial of lapatinib (GW572016) as first-line therapy in patients with advanced or metastatic gastric cancer. Ann Oncol: May 20, 2011 (Epub ahead of print).

13. Cappetta A, Lonardi S, Pastorelli D, Bergamo F, Lombardi G and Zagonel V: Advanced gastric cancer (GC) and cancer of the gastro-oesophageal junction (GEJ): focus on targeted therapies. Crit Rev Oncol Hematol: Jan 19, 2011 (Epub ahead of print).

14. Cunningham D, Humblet Y, Siena S, et al: Cetuximab monotherapy and cetuximab plus irinotecan in irinotecan-refractory metastatic colorectal cancer. N Engl J Med 351: 337-345, 2004.

15. Saltz LB, Meropol NJ, Loehrer PJ Sr, Needle MN, Kopit J and Mayer RJ: Phase II trial of cetuximabin patients with refractory colorectal cancer that expresses the epidermal growth factor receptor. J Clin Oncol 22: 1201-1208, 2004

16. Chou TC and Talalay P: Quantitative analysis of dose-effect relationships: the combined effects of multiple drugs or enzyme inhibitors. Adv Enzyme Regul 22: 27-55, 1984.

17. Yarden Y and Sliwkowski MX: Untangling the ErbB signalling network. Nat Rev Mol Cell Biol 2: 127-137, 2001.

18. Carpenter G and Cohen S: Epidermal growth factor. J Biol Chem 265: 7709-7712, 1999

19. Bonner JA, Harari PM, Giralt J, et al: Radiotherapy plus cetuximab for squamous-cell carcinoma of the head and neck. N Engl J Med 354: 567-578, 2006.

20. Vermorken JB, Mesia R, Rivera F, et al: Platinum-based chemotherapy plus cetuximab in head and neck cancer. N Engl J Med 359: 1116-1127, 2008.
21. Hanna N, Lilenbaum R, Ansari R, et al: Phase II trial of cetuximab in patients with previously treated non-small cell lung cancer. J Clin Oncol 24: 5253-5258, 2006.

22. Lee JC, Wang ST, Chow NH and Yang HB: Investigation of the prognostic value of coexpressed erbB family members for the survival of colorectal cancer patients after curative surgery. Eur J Cancer 38: 1065-1071, 2002.

23. Porebska I, Harlozinska A and Bojarowski T: Expression of the tyrosine kinase activity growth factor receptors (EGFR, ERBB2, ERBB3) in colorectal adenocarcinomas and adenomas. Tumor Biol 21: 105-115, 2002.

24. Bancroft CC, Chen Z, Yeh J, et al: Effects of pharmacologic antagonists of epidermal growth factor receptor, PI3K and MEK signal kinases on NF- $\kappa \mathrm{B}$ and AP-1 activation and IL-8 and VEGF expression in human head and neck squamous cell carcinoma lines. Int J Cancer 99: 538-548, 2002.

25. Raymond E, Fauvre S and Armand JP: Epidermal growth factor receptor tyrosine kinase as a target for anticancer therapy. Drugs 60 (Suppl 1): S15-S23, 2000.

26. Baselga J, Norton L, Masui H, Pandiella A, Coplan K, Miller WH and Mendelsohn J: Antitumor effects of doxorubicin in combination with anti-epidermal growth factor receptor monoclonal antibodies. J Natl Cancer Inst 85: 1327-1333, 1993.

27. Bruns CJ, Harbison MT, Davis DW, et al: Epidermal growth factor receptor blockade with cetuximab plus gemcitabine results in regression of human pancreatic carcinoma growing orthotopically in nude mice by antiangiogenic mechanisms. Clin Cancer Res 6: 1936-1948, 2006

28. Ciardiello F, Bianco R, Damiano V, et al: Antitumor activity of sequential treatment with topotecan and anti-epidermal growth factor receptor monoclonal antibody C225. Clin Cancer Res 4: 909-916, 1999.

29. Fan Z, Baselga J, Masui H and Mendelsohn J: Antitumor effect of anti-EGF receptor monoclonal antibodies plus cis-diamminedichloroplatinum (cis-ddp) on well established A431 cell xenografts. Cancer Res 53: 4637-4642, 1993.

30. Huang SM, Bock JM and Harari PM: Epidermal growth factor receptor blockade with $\mathrm{C} 225$ modulates proliferation, apoptosis, and radiosensitivity in squamous cell carcinomas of the head and neck. Cancer Res 59: 1935-1940, 1999.

31. Huang SM and Harari PM: Modulation of radiation response after epidermal growth factor receptor blockade in squamous cell carcinomas: inhibition of damage repair, cell cycle kinetics, and tumor angiogenesis. Clin Cancer Res 6: 2166-2174, 2000.

32. Inoue K, Slaton JW, Perrotte P, et al: Paclitaxel enhances the effects of the anti-epidermal growth factor receptor monoclonal antibody ImClone C225 in mice with metastatic human bladder transitional cell carcinoma. Clin Cancer Res 6: 4874-4884, 2000.

33. Prewett MC, Hooper AT, Bassi R, Ellis LM, Waksal HW and Hicklin DJ: Enhanced antitumor activity of anti-epidermal growth factor receptor monoclonal antibody IMCC 225 in combination with irinotecan (CPT-11) against human colorectal tumor xenografts. Clin Cancer Res 8: 994-1003, 2002.

34. Shin DM, Donato NJ, Perez-Soler R, et al: Epidermal growth factor receptor-targeted therapy with $\mathrm{C} 225$ and cisplatin in patients with head and neck cancer. Clin Cancer Res 7: 1204-1213, 2001.

35. Han SW, Oh DY, Im SA, Park SR, Lee KW, Bang YJ and Kim TY: Phase II study and biomarker analysis of cetuximab combined with modified FOLFOX6 in advanced gastric cancer. Br J Cancer 100: 298-304, 2009. 